\title{
A regulação do tempo de trabalho na administração pública no contexto da crise e da intervenção da Troika: entre negociação coletiva e unilateralismo estatal
}

\author{
Paulo Marques Alves \\ paulo.alves@iscte.pt \\ ICTE-IUL e DINÂMIA'CET-IUL \\ Helena Pina \\ hpinamaster@gmail.com
}

ISCTE-IUL

\begin{abstract}
Resumo
Questão central das relações laborais, o tempo de trabalho constitui um enjeu conflitual, com os sindicatos a visarem a sua redução e o patronato a enfatizar a necessidade da sua flexibilização. Nas últimas décadas tem-se assistido a uma sua profunda reorganização, com a introdução de mecanismos de flexibilização. Simultaneamente, verifica-se um processo de reestruturação da administração pública. O padrão tradicional, consistindo na definição de um período normal de trabalho semanal distribuído por cinco dias sem recurso a modalidades de flexibilização, apresenta-se atualmente com crescente variabilidade, em resultado da sua introdução. Este panorama regista-se igualmente na administração pública, onde as convenções coletivas que as acolhem são maioritárias no período temporal considerado (2009-outubro de 2015). Após o Acórdão do Tribunal Constitucional de outubro de 2015, centenas de convenções não homologadas pelo governo de direita começaram a ser publicadas, pelo que o padrão das 35 horas em cinco dias sem recurso à flexibilização passará a ser dominante. No entanto, ele manter-se-á profundamente estilhaçado, dado o peso relevante que as convenções que a preveem continuarão a possuir.
\end{abstract}

Palavras chave: Administração pública, relações laborais, negociação coletiva, tempo de trabalho

\section{Introdução}

Questão central das relações laborais, o tempo de trabalho constitui um enjeu conflitual, com os sindicatos a visarem a sua redução, no quadro de uma estratégia de criação de emprego, e o patronato a enfatizar a necessidade da sua flexibilização no âmbito de uma flexibilização da relação salarial para assegurar a competitividade das empresas.

Nas últimas décadas tem-se assistido a uma profunda reorganização do tempo de trabalho, com a introdução de mecanismos de flexibilização, o que vem sendo regulado segundo vários modelos que articulam negociação coletiva, intervenção estatal e processos de concertação social. Simultaneamente, desde o começo da "revolução" neoliberal, a administração pública tem estado sob forte pressão. Partindo da premissa "menos estado, melhor estado", posição para a qual "there is no alternative", como afirmava Thatcher, por toda a Europa iniciou-se um processo no sentido da sua reestruturação (Treu, 1987; Pitschas, 2003). Esta dá-se sob o ímpeto da conceção do New Public Management, devedora da teoria da agência (Bordogna, 2008). 
Nos anos mais recentes, com um neoliberalismo cada vez mais agressivo e no quadro das políticas de austeridade, este programa de "espoliação do Estado", como o designou Petrella (1996) ou de "destruição metódica dos coletivos", nas palavras de Bourdieu (1998), aprofundouse induzindo uma extensa transformação das relações laborais neste setor.

Como refere Bordogna (2008), os grandes objetivos são proceder, por um lado, à convergência das relações laborais entre o setor público e o privado no interior de cada estado nação e, por outro, a uma convergência entre os setores públicos dos vários países. Acompanhando este processo, reforça-se o unilateralismo governamental.

$\mathrm{Na}$ administração pública portuguesa as relações laborais também se modificaram profundamente nos anos mais recentes, primeiro sob o impulso do New Public Management, visando o cumprimento das metas do Pacto de Estabilidade e Crescimento, e depois no contexto da crise iniciada em 2008 e da intervenção da Troika. Todas estas mudanças não deixaram de colocar dificuldades dos sindicatos, que face a elas têm vindo a adotar estratégias e táticas diferenciadas (Stoleroff, 2007, 2013).

Neste setor, as condições de trabalho foram tradicionalmente definidas por via legislativa, em consonância com os vínculos contratuais existentes. Com a aproximação do seu regime laboral ao do sector privado, o direito à contratação coletiva foi outorgado pela Lei n. ${ }^{\circ}$ 23/2004 de 22-06, mas somente aos trabalhadores com contrato de trabalho em funções públicas. Contudo, quer este diploma quer depois a Lei n. ${ }^{\circ}$ 59/2008 de 11-09 (RCTFP $\left.{ }^{1}\right)$ e a Lei n. ${ }^{\text {o }}$ 35/2014 de 20-06 $\left(\right.$ LGTFP $\left.^{2}\right)$ impuseram algumas especificidades.

Atendendo ao objetivo a que nos propusemos, o de compreender o modo como se vem processando a regulação do tempo de trabalho na administração pública através da negociação coletiva, procedemos a uma análise documental de carácter extensivo incidindo sobre o clausulado das 288 convenções negociais publicadas no Diário da República entre 2009 e Outubro de 2015. Outros documentos foram igualmente mobilizados, mormente a legislação produzida e documentos sindicais.

\footnotetext{
${ }^{1}$ Regime do Contrato de Trabalho em Funções Públicas.

${ }^{2}$ Lei Geral do Trabalho em Funções Públicas.
} 
Serão retiradas algumas conclusões relevantes no atinente aos padrões de regulação existentes. Não deixará de ser igualmente evidenciada a política unilateral seguida pelo governo de direita a partir de 2013. Depois de impor as 40 horas de trabalho semanais, o executivo recusou-se a homologar algumas centenas de convenções livremente negociadas, em particular nas autarquias locais do continente, que previam a manutenção das 35 horas. Perto do final do mandato, admitiu a sua possibilidade em troca da aceitação pelos sindicatos da introdução de mecanismos de flexibilização do tempo de trabalho, nomeadamente a adaptabilidade e o banco de horas. Alguns sindicatos e um conjunto de autarquias locais aceitaram a proposta, tendo sido negociadas e assinadas cerca de quatro dezenas de convenções.

De sublinhar ainda que em meados de outubro de 2015 se assistiu à declaração de inconstitucionalidade da norma que permitiu ao governo de Passos Coelho não homologar as convenções prevendo as 35 horas sem a introdução de mecanismos de flexibilização. Com o Acórdão n. ${ }^{\circ}$ 949/2015 do Tribunal Constitucional ficava aberto o caminho para a publicação das várias centenas de instrumentos de regulamentação coletiva vetados desde os finais de 2013.

\section{A Administração pública portuguesa}

A administração pública portuguesa estrutura-se segundo três níveis - central, regional e local desde a implantação do regime democrático. Os dois últimos constituem a administração pública autónoma, nos termos que são conferidos pela Constituição da República Portuguesa e por legislação específica. Os três níveis obedecem a um modelo organizacional idêntico, onde se distinguem serviços relativos à administração direta e outros à administração indireta do Estado.

Este modo de estruturação permanece apesar das profundas mudanças entretanto ocorridas. Mudanças que originaram uma diminuição de efetivos (Quadro 1), cortes salariais (segundo os sindicatos, a desvalorização salarial pelo aumento da jornada de trabalho para as 40 horas teria ascendido a $14,3 \%$ e a $17,9 \%$ somando a supressão de três dias de férias e de quatro feriados) e perdas de outros direitos para os trabalhadores. Paralelamente, aumentou a precariedade, com o número de contratos a termo a passar de 69674 em 2014 para 71723 em 2015 (DGAEP, 2016). 
Quadro 1 - Evolução do emprego público (1996-2015)

\begin{tabular}{lcccccccc}
\hline Ano & $\mathbf{1 9 9 6}$ & $\mathbf{1 9 9 9}$ & $\mathbf{2 0 0 5}$ & $\mathbf{2 0 1 1}$ & $\mathbf{2 0 1 2}$ & $\mathbf{2 0 1 3}$ & $\mathbf{2 0 1 4}$ & $\mathbf{2 0 1 5}$ \\
\hline Efetivos & 639044 & 716418 & 747418 & 727629 & 699828 & 674661 & 656056 & 658565 \\
\hline Fonte:
\end{tabular}

Fonte: DGAEP (2008), para 1996, 1999 e 2005; DGAEP (2016), para os restantes anos

No plano organizacional, as mudanças foram introduzidas por um conjunto de peças legislativas, entre as quais se contam a RCM n. ${ }^{\circ}$ 124/2005 de 04-08 que instituiu o PRACE 3 , o qual visava a "racionalização dos serviços", tendo tido como resultado uma redução do seu número na ordem dos 36,1\% (CT do PRACE, 2006), a que sucedeu o PREMAC ${ }^{4}$; a Lei n. . 3/2004 de 15-01, a leiquadro dos institutos públicos, alvo de sucessivas revisões posteriores, a última das quais data de 2015 com o DL n. 96/2015 de 29-05; a Lei n. * 4/2004 de 15-01, que estabeleceu os princípios e as normas a observar pela administração direta do Estado, também sujeita a várias alterações, a última das quais pela Lei n. ${ }^{\circ}$ 64/2011 de 22-12; o DL n. ${ }^{\circ}$ 200/2006 de 25-10, que estabeleceu o regime geral relativo à extinção, fusão e reestruturação dos serviços públicos, bem como a "racionalização" dos seus efetivos ou a RCM n. 39/2006 de 21-04, que consagrou um conjunto de orientações para a reestruturação dos vários ministérios.

\section{As novas relações de trabalho na administração pública}

No campo das relações laborais, o desejo de proceder à convergência entre os sectores público e privado, implicando a harmonização das disposições legais relativas à administração pública com o estipulado no Código do Trabalho, se bem que com os ajustamentos considerados necessários, conduziu a uma intensa produção legislativa que ocupou os últimos governos.

Os diplomas fundadores desta transformação datam de meados/finais da década passada. Entre eles conta-se a Lei n. ${ }^{\circ}$ 23/2004 de 22-06, que instituiu o regime jurídico do contrato individual de trabalho. Esta lei marcou o início do fim do modelo estatutário até então vigente na administração pública e iniciou uma nova era na qual passaram a coexistir dois grupos de trabalhadores: os que se mantém no regime de nomeação - que se constituiu como a forma típica de relação contratual na administração pública, significando que um trabalhador se encontrava

\footnotetext{
3 Programa de Reestruturação da Administração Central do Estado.

4 Plano de Redução e Melhoria da Administração Central do Estado.
} 
adstrito a um lugar de quadro de carácter permanente, o que lhe conferia o estatuto de "funcionário público" - e os que passam a ter um "contrato individual de trabalho em funções públicas", podendo revestir a modalidade de contrato por tempo indeterminado ou de contrato a termo resolutivo certo ou incerto. Este diploma foi revogado quatro anos mais tarde pela Lei n. ${ }^{\circ}$ 59/2008 de 11-09, a qual seria por sua vez revogada pela Lei n. ${ }^{\circ}$ 35/2014 de 20-06, que visou reunir o essencial do regime laboral dos trabalhadores da administração pública e que vai atualmente na sua quarta versão, com a Lei n. ${ }^{\circ} 84 / 2015$ de 07-08.

A estes diplomas juntam-se a Lei n. ${ }^{\circ} 12-\mathrm{A} / 2008$ de 27-02 $\left(\mathrm{LVCR}^{5}\right)$; a Lei n. ${ }^{\circ}$ 66-B/2007, de 2812 (SIADAP $\left.^{6}\right)$ e a Lei n. ${ }^{\circ}$ 53/2006 de 7-12, tendo por objetivo regular os regimes de mobilidade dos funcionários entretanto criados.

A LVCR, que continua em vigor, limita o regime de nomeação às funções de soberania e de segurança interna, institui dois tipos, as "carreiras especiais" e as "carreiras gerais", reduzindo estas drasticamente a apenas três - técnico superior; assistente técnico e assistente operacional e consagra a existência de uma remuneração base, organizada segundo uma tabela única contendo a totalidade dos níveis salariais, e de suplementos remuneratórios a serem criados e regulamentados por lei ou através da negociação coletiva, no caso dos contratos individuais de trabalho em funções públicas. O mesmo pode suceder com a adaptação ou a criação de sistemas específicos de avaliação do desempenho e a definição de sistemas de recompensa do desempenho diferentes dos estipulados por lei.

O direito à negociação e contratação coletivas na administração pública foi introduzido com este novo quadro regulador, o que foi explicado à época como constituindo um corolário lógico da adoção do contrato enquanto modo de relação contratual dominante. Assim se concluiu um longo processo iniciado em 1976 com a Constituição e que passou por várias etapas.

Outorgando a Constituição um conjunto de direitos de representação consubstanciados nas comissões de trabalhadores e nos sindicatos, bem como o direito de greve e à negociação e contratação coletivas, na administração pública foi necessário esperar uma década para que o DL n. ${ }^{\circ}$ 45-A/84 de 03-02 viesse regulamentar o exercício da liberdade sindical neste setor e garantir

\footnotetext{
${ }^{5}$ Lei dos Vínculos, Carreiras e Remunerações.

${ }^{6}$ Sistema Integrado de Gestão e Avaliação do Desempenho na Administração Pública.
} 
o direito de intervenção sindical segundo duas modalidades: a participação e a negociação coletiva. As matérias reservadas à participação diziam respeito à elaboração da legislação e ao controlo da execução dos planos económico-sociais, enquanto à negociação coletiva ficava reservada matéria de natureza salarial e conexa. No entanto, o resultado do processo negocial só produzia efeitos a partir da regulamentação por via legislativa, pelo que não se consagrava verdadeiramente o direito à contratação coletiva.

Em 1998, o supracitado decreto-lei foi revogado pela Lei 23/98 de 26-05, com exceção do art. ${ }^{\circ}$ 10. Esta lei veio estabelecer o regime de negociação coletiva e de participação dos trabalhadores da administração pública em regime de direito público, definindo quais as matérias passíveis de negociação coletiva (as relativas ao estatuto dos trabalhadores), quais as que poderiam ser objeto de participação e quais eram excluídas (matérias referentes à estrutura, atribuições e competências da administração pública). Nela afirmava-se igualmente que os direitos de negociação coletiva e de participação dos trabalhadores da administração pública em regime de direito privado se regeriam pela legislação geral. Institui-se, deste modo, um sistema dual de negociação coletiva.

Com a Lei n. ${ }^{\circ}$ 23/2004 de 22-06, paralelamente à instituição do regime jurídico do contrato individual de trabalho, outorgou-se simultaneamente aos trabalhadores da administração pública com este tipo de vínculo o direito à negociação e à contratação coletiva, consagrando-se a possibilidade de serem celebradas convenções a vários níveis: contratos coletivos nacionais; contratos coletivos setoriais; acordos coletivos setoriais e acordos de pessoa coletiva pública.

Apesar da sua revogação pela Lei n. ${ }^{0}$ 59/2008 de 11-09, a qual seria por sua vez foi revogada pela Lei n. ${ }^{\circ}$ 35/2014 de 20-06, o direito à negociação e à contratação coletivas foi mantido.

Segundo a LGTFP, o direito dos trabalhadores com vínculo de emprego público à negociação coletiva é "exercido exclusivamente pelas associações sindicais", uma das estruturas de representação coletiva dos trabalhadores consideradas por esta lei, a par das comissões de trabalhadores, às quais se aplica o regime do Código do Trabalho, com as "necessárias adaptações e as especificidades constantes da presente lei”. Com ela visa-se a obtenção de um acordo que origine um instrumento de regulamentação coletiva. Este constitui uma fonte específica do contrato de trabalho em funções públicas, sendo a este propósito feita uma 
remissão para o Código do Trabalho, afirmando-se que as suas disposições sobre a relação entre a lei e os instrumentos de regulamentação coletiva e entre aquelas fontes e o contrato de trabalho em funções públicas são aplicáveis ao vínculo de emprego público, mais uma vez "sem prejuízo do disposto na presente lei e com as necessárias adaptações".

Constituem instrumentos de regulamentação coletiva de trabalho convencionais o acordo coletivo de trabalho, o acordo de adesão e a decisão de arbitragem voluntária. Os acordos coletivos de trabalho são de dois tipos: o acordo coletivo de carreira (quando se aplica a uma carreira ou conjunto de carreiras, independentemente dos serviços onde os trabalhadores exercem funções, podendo as carreiras ser especiais ou gerais) e o acordo coletivo de empregador público (quando se aplica apenas a um serviço). A decisão de arbitragem necessária é um instrumento não convencional. Face à legislação anterior, desapareceu o regulamento de extensão procedendo esta lei inclusivamente à revogação do regulamento de extensão emitido ao abrigo da legislação revogada. Atualmente, os acordos coletivos de trabalho aplicam-se em primeira instância aos trabalhadores filiados nos sindicatos que os outorgam e a todos os trabalhadores da carreira ou do serviço em causa, salvo se se verificar uma "oposição expressa" por parte de cada trabalhador ou de uma outra associação sindical com legitimidade para celebrar uma convenção coletiva.

A LGTFP mantém esta noção de legitimidade, que já se encontrava no diploma que foi revogado, sendo que a legitimidade para participar nos processos negociais assenta na introdução de um princípio de representatividade.

Seguindo o diploma revogado, a lei em vigor acolhe igualmente o princípio da articulação entre convenções, com os $\mathrm{ACC}^{7}$ a balizar as matérias que podem ser reguladas pelos $\mathrm{ACEP}^{8}$. Na ausência do primeiro tipo de convenção ou da definição das matérias que podem ser reguladas, um ACEP apenas pode regular as matérias relativas à segurança e saúde no trabalho e à duração e organização do tempo de trabalho, excluindo as respeitantes a suplementos remuneratórios.

\footnotetext{
7 Acordo Coletivo de Carreira.

${ }^{8}$ Acordo Coletivo de Empregador Público.
} 
O processo iniciou-se de forma muito titubeante com a assinatura de um $\mathrm{ACCG}^{9}$ e de um $\mathrm{ACCE}^{10}$, ambos em 2009, e assim se manteve até 2013, com apenas 40 convenções publicadas no espaço de cinco anos, como evidencia o Gráfico 1. A partir de 2014 dá-se um fortíssimo crescimento, que será indissociável da imposição das 40 horas de trabalho semanais na administração pública, através da Lei n. ${ }^{\circ}$ 68/2013 de 29-08. No seu seguimento verifica-se uma explosão negocial na administração regional e na administração local dos Açores e da Madeira, particularmente acentuada na primeira das regiões autónomas, à quem cabem 127 das 156 convenções assinadas nesse ano (81,4\%), sendo 97 relativas à administração regional e 30 à administração local. Na Madeira, as 29 convenções publicadas referem-se à administração local. Todas elas preveem 35 horas de trabalho semanal. Se o governo da República bloqueou as convenções que no continente previam este período normal de trabalho diário, assim torpedeando o princípio da livre negociação entre as partes e a autonomia do poder local, tal não sucedeu ao nível regional. Neste ano, relativamente ao continente, só foi publicada uma convenção, a qual previa 40 horas de trabalho semanal ${ }^{11}$.

Gráfico 1 - Evolução do número de convenções coletivas negociais publicadas entre 2009 e outubro de 2015

\footnotetext{
${ }_{9}$ ACCG - Acordo Coletivo de Carreiras Gerais, que foi subscrito pela FESAP - Federação de Sindicatos da Administração Pública e de Entidades com Fins Públicos, que agrupa 19 sindicatos, na sua quase totalidade filiados na UGT, e de que o principal é o SINTAP Sindicato dos Trabalhadores da Administração Pública e de Entidades com Fins Públicos, e pela FS - Frente Sindical, composta pelo STE - Sindicato dos Quadros Técnicos do Estado e de Entidades com Fins Públicos, filiado na UGT, e mais cinco organizações não filiadas confederalmente.

10 ACCE - Acordo Coletivo de Carreira Especial. Foi subscrito pela FNAM - Federação Nacional dos Médicos, próxima da CGTP-IN, e pelo SIM - Sindicato Independente dos Médicos, sendo aplicável à carreira médica.

${ }^{11}$ Trata-se do ACEP dos Serviços de Apoio Técnico e Administrativo da Procuradoria-Geral da República e do Gabinete de Documentação e Direito Comparado, assinada pelo STE.
} 




Fonte: Base de dados das convenções coletivas da administração pública

Em 2015 manteve-se a mesma tendência até outubro. Na sequência da lei das 40 horas, o Provedor de Justiça requereu a inconstitucionalidade da norma que previa a intromissão do governo na celebração das convenções coletivas ao nível autárquico, norma que acabou por ser declarada inconstitucional pelo Acórdão n. ${ }^{\circ}$ 949/2015 do Tribunal Constitucional, publicado no

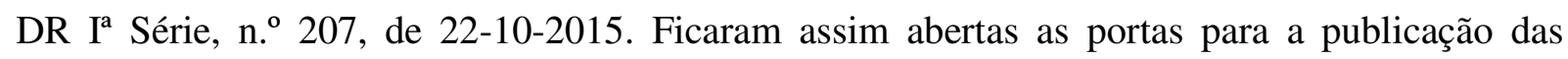
centenas de convenções ${ }^{12}$ que haviam sido objeto de veto pelo governo.

\section{A regulação do tempo de trabalho na administração pública}

Todas as convenções analisadas incluem disposições relativas à duração e organização do tempo de trabalho, sendo que somente quatro preveem uma duração semanal do período normal de trabalho de 40 horas $^{13}$, tal como imposto unilateralmente em 2013 e com consagração posterior

\footnotetext{
${ }^{12}$ De acordo com o sítio do STAL - Sindicato Nacional dos Trabalhadores da Administração Local e Regional na Internet, em Novembro de 2014 o número de convenções coletivas negociadas na administração local e não publicadas por preverem as 35 horas de trabalho semanal ascendia a 509 (182 em câmaras municipais; 309 em juntas de freguesia; doze em serviços municipalizados e seis em outros órgãos da administração local, como as comunidades intermunicipais).

13 ACCE Médica; ACCE Médica (Madeira), assinado pelo SIM e pelo SMZS - Sindicato dos Médicos da Zona Sul; ACEP dos Serviços de Apoio Técnico e Administrativo da Procuradoria-Geral da República e do Gabinete de Documentação e Direito Comparado e
} 
na LGTFP, no seu art. ${ }^{\circ} 105^{\circ}$, ainda que no seu n. 3 se refira que ele possa ser reduzido através de convenção coletiva, do que não poderá resultar a diminuição da retribuição dos trabalhadores.

As restantes, ou porque foram rubricadas antes da entrada em vigor da lei ou porque se aplicam às administrações regionais dos Açores ou da Madeira ou a autarquias locais destas duas regiões preveem as 35 horas de trabalho semanal. O mesmo sucede com 44 convenções $^{14}$ assinadas já perto do final do mandato do governo de Passos Coelho, quando este decidiu que seria possível rubricar acordos estipulando 35 horas de trabalho em troca da adoção de mecanismos de flexibilização do horário de trabalho.

A LGTFP, no seu art. ${ }^{\circ} 101 .^{\circ}$ define que nas matérias atinentes ao tempo de trabalho e respetiva organização se aplica aos trabalhadores com vínculo de emprego público o regime previsto no Código do Trabalho, ressalvando-se que tal sucede com as devidas adaptações e sem prejuízo do definido nos artigos subsequentes desta lei.

Este diploma no seu art. ${ }^{\circ} 110 .^{\circ}$ tipifica um conjunto de modalidades de horário de trabalho, referindo expressamente o flexível; o rígido; o desfasado; a jornada contínua, os horários específicos e o trabalho por turnos, que são definidos nos artigos seguintes. $\mathrm{O}$ mesmo sucede com a isenção de horário (art. $.^{\circ} 117 .^{\circ}$ e $118 .^{\circ}$ ), a não sujeição a horário de trabalho (art. ${ }^{\circ} 119 .^{\circ}$ ) e o trabalho suplementar ( art. $^{\circ} 120 .^{\circ}$ e $121 .^{\circ}$ ). Não existe nesta lei nenhuma norma sobre o trabalho noturno, fazendo-se a respetiva remissão para o Código do Trabalho.

A generalidade das convenções acolhe estas modalidades, em particular a jornada continua (99,3\%); o horário flexível (99,0\%); o trabalho suplementar (97,2\%); o horário rígido $(95,5 \%)$ e o horário desfasado $(93,1 \%)$. As que se encontram menos presentes são o trabalho por turnos $(65,7 \%)$ e o horário noturno $(55,4 \%)$, o que é explicável pelo facto de que muitas das convenções se aplicam a serviços da administração regional, em particular nos Açores. Com uma presença intermédia surgem os horários específicos $(77,9 \%)$, destinados a trabalhadores abrangidos pelo

ACEP da Secretaria-Geral do Ministério da Solidariedade Emprego e Segurança Social, subscrito pelo STE.

14 Trata-se de 38 convenções em câmaras municipais; três em serviços municipalizados, duas em comunidades intermunicipais e uma numa junta de freguesia, incidindo particularmente na região centro do país (distritos de Leiria, Santarém e Coimbra) e assinadas pelo SINTAP e, em alguns casos, também pelo STE e pelo SNBP - Sindicato Nacional dos Bombeiros Profissionais. 
regime da parentalidade, trabalhadores-estudantes e outros trabalhadores que exerçam funções cuja natureza não permita enquadrar os seus horários nas restantes modalidades, e a isenção de horário (82,7\%). Regra geral segue-se o que se encontra legislado, havendo no entanto convenções que estabelecem outras normas, atendendo fundamentalmente às especificidades dos serviços, nomeadamente no que se refere ao trabalho por turnos. Três convenções estipulam ainda o regime de prevenção e chamada ${ }^{15}$; outras três o regime de disponibilidade ${ }^{16}$.

Como se pode observar no Quadro 2, a organização do tempo de trabalho reveste vários regimes, o que representa o estilhaçar do padrão tradicional assente na definição de um período normal de trabalho semanal distribuído por cinco dias. O quadro revela igualmente a relevância adquirida pelos dois mecanismos de flexibilização do tempo de trabalho definidos pela legislação, a adaptabilidade e o banco de horas, na contratação coletiva da administração pública. Inclusivamente, existem 29 instrumentos de regulamentação coletiva que acolhem ambos ${ }^{17}$.

Quadro 2 - Regimes de organização do tempo de trabalho previstos nas convenções coletivas negociais da administração pública entre 2009 e outubro de 2015

\begin{tabular}{|l|c|c|}
\hline \multicolumn{1}{|c|}{ Regimes } & N. $^{\circ}$ & $\%$ \\
\hline 35 horas semanais sem adaptabilidade nem banco de horas & 92 & 31,9 \\
\hline 35 horas semanais com adaptabilidade & 32 & 11,1 \\
\hline 35 horas semanais com banco de horas & 130 & 45,1 \\
\hline 35 horas semanais com adaptabilidade e banco de horas & 29 & 10,1 \\
\hline 40 horas semanais sem adaptabilidade nem banco de horas & 3 & 1,0 \\
\hline 40 horas semanais com adaptabilidade & 1 & 0,3 \\
\hline 40 horas semanais com banco de horas & 1 & 0,3 \\
\hline
\end{tabular}

${ }^{15}$ ACCE Médica; ACCE Médica (Madeira); ACCG do serviço de saúde da Região Autónoma da Madeira, EPE.

${ }^{16}$ ACCE Médica e dois ACEP paralelos na Assembleia Legislativa da Região Autónoma dos Açores, um subscrito pelo SINTAP e outro pelo STFPSSRA - Sindicato dos Trabalhadores em Funções Públicas e Sociais do Sul e Regiões Autónomas.

17 Trata-se basicamente das convenções assinadas nas autarquias locais dos distritos de Leiria, Santarém e Coimbra já mencionadas, a que se juntam os dois ACEP paralelos da Câmara Municipal do Funchal, um rubricado pelo STFP-RAM - Sindicato dos Trabalhadores da Função Pública da Região Autónoma da Madeira e outro pela FESAP e pelo SNBP. 
0

Fonte: Base de dados das convenções coletivas da administração pública

No que diz respeito à adaptabilidade, a Lei n. ${ }^{0}$ 59/2008 de 11-09 já a admitia. Como referimos, este diploma foi revogado pela LGTFP. Esta, no art. $^{\circ} 106 .^{\circ}$, afirma expressamente que se aplicam aos trabalhadores com contrato de trabalho em funções públicas os regimes de adaptabilidade e de banco de horas nas suas versões individual e grupal, de acordo com o que se encontra previsto no Código do Trabalho, com as devidas adaptações. Por sua vez, aos trabalhadores nomeados aplicam-se os regimes da adaptabilidade e de banco de horas individuais, também de acordo com o que se encontra definido no Código do Trabalho, igualmente com as devidas adaptações.

O Código do Trabalho, no art. ${ }^{\circ} 204 .^{\circ}$, estabelece que por convenção coletiva é possível definir um período normal de trabalho em termos médios, em que o limite diário pode aumentar até quatro horas e o semanal até 60, não contando para este cômputo o trabalho suplementar prestado por motivo de força maior e não podendo o período normal de trabalho exceder as 50 horas em média num período de dois meses. Preveem-se regimes de carácter individual e grupal.

No primeiro, fixado no art. $^{\mathrm{o}} 205$. $^{\mathrm{o}}$, mediante uma proposta por escrito do empregador, este e os trabalhadores individualmente considerados podem acordar o acréscimo do período normal de trabalho em duas horas diárias e num máximo de 50 semanais, mais uma vez não contando para este cômputo o trabalho suplementar prestado por motivo de força maior. Nas semanas em que a duração do período normal de trabalho for inferior a 40 horas, a redução pode ir até às duas horas diárias ou então, por acordo entre as partes, proceder-se a uma compensação em dias ou meiosdias, sem que o trabalhador deixe de beneficiar do subsídio de refeição.

No segundo, abordado no art. $.^{\circ} 206 .^{\circ}$, a convenção coletiva pode prever a aplicação do regime ao conjunto dos trabalhadores de uma dada unidade orgânica se, pelo menos, $60 \%$ desses trabalhadores forem por ele abrangidos "mediante filiação em associação sindical celebrante da convenção e por escolha dessa convenção como aplicável” ou a todos os trabalhadores dessa unidade, no caso de $75 \%$ o aceitarem. 
O código exclui da aplicação deste regime os trabalhadores que estejam abrangidos por convenções coletivas que em relação a ele "disponham de modo contrário", os trabalhadores que sejam representados por associações sindicais que tenham "deduzido oposição" a portarias de extensão da convenção e a trabalhadores com filhos com menos de três anos que não manifestem por escrito a sua aceitação.

No seu art. $^{\circ} 207 .^{\circ}$, este diploma contém uma norma que institui a necessidade de um período de referência. Estabelece que este deve ser definido por convenção coletiva, não podendo ser superior a doze meses. Na sua ausência convencionam-se quatro meses e seis para situações que são tipificadas. Consagra-se ainda o princípio da não possibilidade de alteração do período de referência durante o seu decurso, a não ser em circunstâncias especiais.

Como se depreende do Quadro 2, existem 62 convenções (21,5\% do total analisado) que acolhem o regime da adaptabilidade, sendo que 46 referem a possibilidade de celebração de acordos individuais. Do lado da UGT, o SINTAP rubricou 39, mais dezasseis através da FESAP, e o STE nove, mais uma através da FS. Do lado da CGTP, o STFPSN ${ }^{18}$ assinou quatro a que acresce uma outra através da federação em que se encontra filiado, a FNSTFPS ${ }^{19}$.

Em termos gerais, acolhem as disposições plasmadas no Código do Trabalho, sem que se verifiquem grandes desenvolvimentos. Por exemplo, no que atinente ao período de referência, a esmagadora maioria dos instrumentos (57) refere quatro meses e dois (ACCE Médica e ACCG) seis meses. Constituem exceção a esta regra os dois ACEP paralelos da câmara do Funchal, que estabelecem dois meses e o ACEP do Instituto da Segurança Social, IP, que fixa os três meses.

As durações máximas previstas são variadas (40, 45, 48 ou 50 horas), só havendo três convenções que admitem o máximo de 60 horas previsto no Código do Trabalho, não podendo exceder as 50 horas em média num período de dois meses ${ }^{20}$.

\footnotetext{
${ }^{18}$ STFPSN - Sindicato dos Trabalhadores em Funções Públicas e Sociais do Norte.

19 FNSTFPS - Federação Nacional dos Sindicatos dos Trabalhadores em Funções Públicas e Sociais.

${ }^{20}$ Trata-se de dois ACEP paralelos aplicáveis à câmara de Ponta Delgada, um subscrito pelo SINTAP e outro pelo SNPM - Sindicato Nacional das Polícias Municipais, e do ACCG do Serviço de Saúde da Madeira. O instrumento que prevê o menor limite máximo (40 horas) é o ACEP do Instituto da Segurança Social, IP rubricado pelo SINTAP numa altura em que ainda vigorava o período normal de trabalho de 35 horas.
} 
A generalidade das convenções onde se prevê a adaptabilidade acolhe a norma do código segundo a qual nas semanas em que a duração do período normal de trabalho for inferior a 35 horas (a referência é sempre às 35 horas), o horário pode ser reduzido em duas horas ou em dias ou meios-dias sem prejuízo do subsídio de refeição, mas só o ACCG do Serviço de Saúde da Madeira se refere à possibilidade dessa redução se basear exclusivamente na concessão de dias ou de meios-dias.

Algumas das convenções que acolhem a adaptabilidade, restringem-na de alguma forma. É o caso do ACEP da câmara de Lisboa ${ }^{21}$, que determina que ela não se aplica aos bombeiros profissionais. Dois outros instrumentos ${ }^{22}$ só a consideram por ocasião da realização de determinados eventos. Outros nove ${ }^{23}$ consideram que este regime se aplica unicamente a determinados serviços, em particular os de âmbito cultural (bibliotecas, museus).

De sublinhar ainda que a maioria das convenções onde se admite a adaptabilidade (45 em 62) estabelece a participação sindical na sua implementação, seja por via da informação (em dez casos) ou da consulta (em 35).

O segundo regime de modulação do tempo de trabalho consagrada pelo Código do Trabalho é o banco de horas. No art. $^{\circ} 208 .^{\circ}$ determina que a sua instituição se poderá efetivar através da negociação coletiva, com o período normal de trabalho diário a poder ser acrescido até quatro horas e o semanal até 60, definindo-se um limite máximo de 200 horas anuais. À negociação coletiva fica reservada a fixação de normas relativas à compensação do trabalho prestado em acréscimo (redução equivalente do tempo de trabalho, aumento do período de férias ou pagamento em dinheiro); a antecedência com que deve ser comunicada ao trabalhador a necessidade de prestação do acréscimo de trabalho; o período em que a compensação se efetivará; e a antecedência com que deve ser comunicado o período de redução, a solicitação do empregador ou do trabalhador.

\footnotetext{
${ }^{21}$ Assinado pela FESAP e pelo SNBP.

22 Trata-se dos ACEP das câmaras de Ponte de Lima e de Vila Verde, convenções subscritas pelo SINTAP e pelo STFPSN.

23 Trata-se dos ACEP aplicáveis a um conjunto de câmaras do distrito de Leiria (Alcobaça, Alvaiázere, Ansião, Caldas da Rainha, Leiria, Óbidos, Porto de Mós e Batalha) e aos serviços municipalizados de Leira, todos assinados pelo SINTAP (a que se juntou o SNBP no caso de Leiria), subscritos no quadro da troca das 35 horas por adaptabilidade.
} 
O banco de horas pode revestir igualmente um carácter individual ou grupal. De acordo com o regime introduzido pela Lei $n .^{\circ}$ 23/2012 de 25-06, traduzido no art. $^{\circ} 208$. $^{\circ}$-A do Código do Trabalho, o banco de horas individual é passível de ser instituído por acordo entre o trabalhador e o empregador, sob proposta deste por escrito, com o período normal de trabalho a poder ser aumentado até duas horas diárias e 50 semanais com um limite máximo de 150 horas anuais. Os acordos que instituem o banco de horas individual devem também regular os aspetos anteriormente referidos relativos à compensação. O regime do banco de horas grupal, introduzido pela mesma lei e entretanto alterado pela Lei n. ${ }^{\circ}$ 120/2015 de 01-09 e traduzido no art. $^{\circ} 208 .^{\circ}-\mathrm{B}$ do Código do Trabalho, é passível de aplicação nas condições previstas para a adaptabilidade grupal, estando isentos dessa aplicação os trabalhadores que se encontrem nas mesmas circunstâncias das referidas para esse regime de adaptabilidade.

Do Quadro 2 deduz-se que o banco de horas é o regime de modulação do tempo de trabalho privilegiado na negociação coletiva na administração pública. São 160 as convenções que o estabelecem, sendo que 26 acolhem o banco de horas individual ${ }^{24}$. Trata-se de convenções que foram assinadas maioritariamente por sindicatos da UGT (107, de que se destaca o SINTAP com 73), mas existem igualmente dois sindicatos da CGTP que, nos Açores, assinaram convenções que estipulam o banco de horas grupal (o STFPSSRA, a quem cabe 43 instrumentos e o STSS ${ }^{25}$, com nove). Sindicatos não filiados confederalmente assinaram quatro convenções.

Em linha com o que se encontra legislado, a esmagadora maioria das convenções $(86,3 \%)$ preveem um máximo anual de 200 horas, havendo outras catorze que determinam 100 horas e sete que referem 150. No caso de 29 ACEP que se aplicam a unidades de saúde dos Açores, prevê-se que o período normal de trabalho dos trabalhadores em regime de turnos possa ser aumentado até um turno por semana com o limite de 48 horas semanais e 200 anuais. Por sua vez, o ACEP aplicável nas embaixadas e postos consulares, assinado pelo $\mathrm{STCDE}^{26}$, define que o limite anual não pode ultrapassar "o total do número de horas dos dias feriados excedentários".

\footnotetext{
${ }^{24}$ É o que sucede na maioria das convenções já referidas e que se aplicam basicamente em autarquias da região centro, com especial enfoque nos distritos de Santarém e Leiria, a maioria das quais tem por base a troca das 35 horas por mecanismos de adaptabilidade.

${ }^{25}$ Sindicato Nacional dos Técnicos Superiores de Saúde das Áreas de Diagnóstico e Terapêutica.

${ }^{26}$ Sindicato dos Trabalhadores Consulares e das Missões Diplomáticas.
} 
A regulação dos procedimentos relativos à comunicação da necessidade de acréscimo do número de horas de trabalho a efetuar é em regra admitida. A maioria das convenções $(74,4 \%)$ define um período muito curto, atendendo à necessidade de conciliação entre vida familiar e vida profissional, de apenas dois dias. Outros prazos, mais favoráveis, encontram-se previstos, remetendo para uma antecedência mínima de cinco dias, salvo "em caso de força maior" (doze convenções), para uma antecedência de "dez dias seguidos" (duas ${ }^{27}$ ) ou quinze dias (28 convenções $\left.{ }^{28}\right)$.

Em termos da compensação do acréscimo do número de horas trabalhadas, a grande maioria das convenções $(81,9 \%)$ estipula que ele deve ocorrer "durante o ano civil". Com um carácter muito minoritário encontramos a consideração dos 90 dias subsequentes ao período em que se verificou o acréscimo (os dois ACEP da câmara do Funchal); "até ao semestre seguinte" (treze convenções) e "no semestre seguinte" àquele em que ocorreu o acréscimo (quinze). Apenas a convenção aplicável à câmara municipal de Leiria prevê que a compensação possa revestir a forma monetária em vez de o ser em tempo.

A quase totalidade das convenções onde se prevê o banco de horas define os prazos que a serem seguidos, quer pelas entidades patronais quer pelos trabalhadores, para comunicação da redução do tempo de trabalho como compensação dos acréscimos verificados. Do lado patronal, a grande maioria $(74,4 \%)$ fixa os dois dias "salvo em caso de força maior". Uma antecedência mínima de cinco dias, "salvo em caso de força maior devidamente comprovado" é acolhida por onze convenções e os quinze dias por 27. Do lado dos trabalhadores, estes podem requerer por escrito a redução com uma antecedência mínima de dois dias, no caso de 74,4\% das convenções; com cinco dias, para onze; com oito dias, para outras 26 e com dez dias no caso dos dois ACEP da câmara do Funchal. A maioria dos instrumentos $(64,4 \%)$ determina que o pedido de utilização da redução por parte dos trabalhadores só pode ser recusado por "motivos de força maior".

\footnotetext{
27 No caso os ACEP paralelos da câmara do Funchal.

${ }^{28} \mathrm{Na}$ generalidade dos casos, as autarquias da região centro já referenciadas.
} 
Nove convenções ${ }^{29}$ estabelecem que o banco de horas só é admissível em determinados períodos que são especificados, enquanto outras 23 referem a necessidade de existência de "circunstâncias relevantes" que o justifiquem. Outros dois instrumentos ${ }^{30}$ precisam que o banco de horas só é aplicável "fora dos trabalhos parlamentares".

A participação sindical nos processos relacionados com os bancos de horas encontra-se prevista num número muito escasso de convenções (apenas onze) ${ }^{31}$. Em todas elas a modalidade que se encontra definida é a consulta.

\section{Conclusão}

À semelhança de outros países da UE e da OCDE, a administração pública portuguesa tem vindo a ser alvo de mudanças profundas, quer no plano da sua orgânica quer no domínio das relações laborais, impulsionadas pela perspetiva do New Public Management. Ainda que abrindo novas possibilidades aos sindicatos, nomeadamente dada a concessão do direito à contratação coletiva, esta situação não deixou de lhes criar inúmeras dificuldades. Em resposta, as organizações sindicais têm adotado estratégias e táticas nem sempre coincidentes. Em Portugal, é disso elucidativo o facto da FESAP ter assinado o acordo relativo à LVCR e da mesma organização e a FS terem assinado o do SIADAP, o que não sucedeu com a Frente Comum. Acrescente-se que, como bem nota Stoleroff, a negociação desses acordos jamais colocou em causa a conceção governamental sobre a reforma, apenas se tendo limitado a regular alguns dos seus aspetos (Stoleroff, 2007: 650).

Uma peça importante no processo de convergência das relações laborais do setor público com as do setor privado foi a introdução do contrato individual de trabalho em funções públicas, que marcou o fim do modelo estatutário até então vigente. Como seu corolário deu-se a efetivação do direito à contratação coletiva para o grupo de trabalhadores que então se forma com base nesta nova modalidade contratual.

\footnotetext{
29 As que se aplicam às câmaras municipais de Óbidos, Porto de Mós, Vila Pouca de Aguiar, Alcobaça, Caldas da Rainha, Alvaiázere e Ansião e aos serviços municipalizados das Caldas da Rainha, todas assinadas pelo SINTAP.

30 Trata-se das duas convenções paralelas aplicáveis à Assembleia Legislativa da Região Autónima dos Açores.

${ }^{31}$ Trata-se dos ACEP aplicáveis às câmaras municipais de Almeirim, Alvaiázere, Ansião, Leiria, Mação, Mértola, Porto de Mós, Rio Maior e Tábua, à comunidade intermunicipal da Lezíria do Tejo e aos serviços municipalizados de Leiria, todos rubricados pelo SINTAP.
} 
Como referimos, o processo iniciou-se de forma titubeante, com as primeiras convenções a datarem de 2009, consubstanciando-se num ACCG e num ACCE. Dada a introdução do princípio da articulação entre convenções, em que as de nível superior (os ACC, que possuem âmbito nacional) definem as matérias a serem objeto de negociação e acordo por parte das convenções de nível inferior (ACEP, negociados e assinados descentralizadamente ao nível dos serviços), a negociação tem-se restringido basicamente às questões do tempo de trabalho e da segurança e saúde no trabalho, atendendo ao conteúdo do ACCG assinado em 2009.

Para além desta limitação, as convenções na administração pública denotam duas características que tradicionalmente têm estado presentes na negociação coletiva no setor privado: o paralelismo convencional e a reprodução da lei, não existindo praticamente qualquer desenvolvimento face a esta. Esse facto é bem patente no que se refere à regulação do tempo de trabalho.

Contrariamente ao que sucede noutros países, onde a negociação coletiva se constitui como a principal fonte de regulação e a intervenção estatal é limitada, em Portugal o Estado tem assumido desde sempre um papel central, daí decorrendo uma extensa regulação de tipo legislativo, nomeadamente no que concerne à organização do tempo de trabalho. E o Estado não se coíbe mesmo de impor a sua política de forma unilateral. No âmbito da administração pública, não só impôs as 40 horas de trabalho em 2013, sem ter encetado qualquer negociação com os sindicatos, como vetou a publicação de centenas de acordos prevendo as 35 horas, em particular nas autarquias locais do continente, assim torpedeando os princípios basilares da livre negociação entre as partes e da autonomia do poder local.

Tradicionalmente assistíamos à existência de um padrão claro no que respeita ao tempo de trabalho. Esse padrão consistia na definição de um período normal de trabalho semanal, por exemplo de 40 horas, distribuídas por cinco dias de trabalho. Atualmente, verifica-se uma crescente variabilidade no seio deste padrão, fruto do recurso a formas diversas de organização/modulação do tempo de trabalho que, no caso da administração pública portuguesa, se materializam na utilização dos regimes da adaptabilidade e do bancos de horas, de carácter grupal ou individual.

Esta é a nossa principal conclusão. As convenções coletivas que acolhem modalidades de flexibilização do tempo de trabalho são maioritárias no período temporal que abarcámos. No 
entanto, após o Acórdão do Tribunal Constitucional de meados de outubro de 2015, as convenções não homologadas pelo governo de Passos Coelho começaram a ser publicadas. Esse facto irá permitir alterar o panorama, dado que a modalidade dominante de organização do tempo de trabalho passará a ser as 35 horas em cinco dias de trabalho sem recurso a qualquer modalidade de flexibilização. No entanto, este padrão manter-se-á profundamente estilhaçado, dado o peso relevante que as convenções que preveem essas modalidades continuarão a possuir.

\section{Bibliografia}

Bach, Stephen; Bordogna, Lorenzo (2013), "Reframing public service employment relations: the impact of economic crisis and the new UE economic governance", European Journal of Industrial Relations, vol. 19, n. ${ }^{\circ}$ 4, pp. 279-284.

Bordogna, Lorenzo (2008), "Moral hazard, transaction costs and the reform of public service employment relations", European Journal of Industrial Relations, vol. 14, n. ${ }^{\circ}$ 4, pp. 381-400.

Bourdieu, Pierre (1998), L’essence du néolibéralisme, Le Monde Diplomatique.

DGAEP (2008), A década. Emprego público em números. 1996-2005, Lisboa, DGAEP.

DGAEP (2016), Síntese estatística do emprego público - $4^{\circ}$ trimestre de 2015, Lisboa, DGAEP.

Pitschas, Rainer (2003), "Reformas da administração pública na União Europeia”, in Mozzicafreddo, Juan e Salis Gomes, João (Eds.), Ética e administração. Como modernizar os serviços públicos?, Oeiras, Celta.

Petrella, Ricardo (1996), Le bien commun, éloge de la solidarité, Bruxelas, Labor.

PRACE (2006), Relatório da Comissão Técnica - Primeira Fase, Lisboa, PRACE.

Prosser, Thomas (2014), "Financialization and the reform of European industrial relations systems", European Journal of Industrial Relations, vol. 20, n. ${ }^{\circ}$, pp. 351-365.

Ramalho, J. Góis (2010), La negociación colectiva en la administración pública. Un estudio jurídico de los sistemas de España e Portugal, Universidade de Salamanca - Faculdade de Direito (Tese de Doutoramento).

Ramalho, M. ${ }^{a}$ do Rosário Palma (2012), Tratado de Direito do Trabalho. Parte III - Situações laborais colectivas, Coimbra, Almedina.

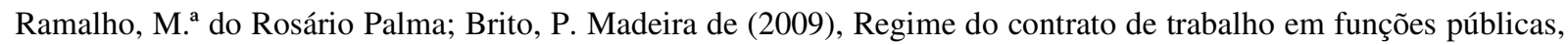
Coimbra, Almedina.

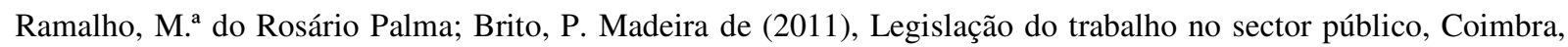
Almedina.

Sousa, R. Correia de (2014), Lei Geral do Trabalho em Funções Públicas anotada e comentada e legislação complementar, Porto, Vida Económica.

Stoleroff, Alan (2007), "The revolution in the public services sector in Portugal: with or without the unions", Transfer, vol. 13, n. ${ }^{\circ}$, pp. 631-652.

Stoleroff, Alan (2013), "Employment relations and unions in public administration in Portugal and Spain: from reform to austerity”, European Journal of Industrial Relations, vol. 19, n. ${ }^{4}$, pp. 309-323.

Treu, Tiziano (1987), Public services labour relations: recent trends and future prospects. A comparative survey of seven industrialized market economy countries, Genebra, OIT. 
Fontes Legislativas:

Constituição da República Portuguesa

DL n. ${ }^{\circ} 45-\mathrm{A} / 84$ de 03-02

Lei 23/98 de 26-05

Lei n. ${ }^{\circ}$ 3/2004 de 15-01

Lei n. ${ }^{\circ}$ 4/2004 de 15-01

Lei n. ${ }^{\circ}$ 23/2004 de 22-06

RCM n. ${ }^{\circ} 124 / 2005$ de 04-08

RCM n. ${ }^{\circ}$ 39/2006 de 21-04

DL n. ${ }^{\circ}$ 200/2006 de 25-10

Lei n. ${ }^{\circ}$ 53/2006 de 7-12

Lei n. ${ }^{\circ}$ 66-B/2007, de 28-12

Lei n. ${ }^{\circ}$ 12-A/2008 de 27-02

Lei n. ${ }^{\circ}$ 59/2008 de 11-09

Lei n. ${ }^{\circ}$ 64/2011 de 22-12

Lei n. ${ }^{\circ}$ 23/2012 de 25-06

Lei n. ${ }^{\circ}$ 68/2013 de 29-08

Lei n. ${ }^{\text {o 35/2014 de 20-06 }}$

DL n. ${ }^{\circ}$ 96/2015 de 29-05

Lei n. ${ }^{\circ} 84 / 2015$ de 07-08

Lei n. ${ }^{\circ}$ 120/2015 de 01-09

Acórdão n. ${ }^{\circ}$ 949/2015 do Tribunal Constitucional 